\title{
Childhood Rituals: Normal Development or Obsessive-Compulsive Symptoms?
}

\author{
HENRIETTA L. LEONARD, M.D., ERICA L. GOLDBERGER, B.A., JUDITH L. RAPOPORT, M.D., \\ DEBORAH L. CHESLOW, B.S., AND SUSAN E. SWEDO, M.D.
}

\begin{abstract}
The symptoms of obsessive compulsive disorder (OCD) have been viewed as extreme variants of normal developmental rituals and superstitiousness; however, difference in timing, content, and severity argue against this continuum. In a systematic comparison of 38 children with severe primary OCD and 22 matched normal controls, parents were interviewed about their child's early developmental rituals and current superstitions. Children were asked about superstitious beliefs. Children with OCD did not differ significantly from controls in number or type of superstitions. However, parents of the OCD children reported significantly more "marked" patterns of early ritualistic behavior than did parents of normal controls. When behaviors resembling primary OCD symptoms were excluded, other rituals did not differ leaving open the possibility that such behaviors were early manifestations of the disorder. Only a prospective study can determine whether these results reflect preclinical OCD or are an artifact of biased recall. J. Am. Acad. Child Adolesc. Psychiatry, 1990, 29, 1:17-23. Key Words: obsessivecompulsive disorder, childhood developmental rituals, superstitions, obsessions, compulsions.
\end{abstract}

Ritualistic play, repetitive behavioral patterns of toddlers, childhood games, and superstitions have all been viewed as related to obsessive compulsive disorder (OCD), with the obsessions and compulsions representing pathological extremes of normal development or of cultural phenomena (Peller, 1954). Despite references to this continuum in major psychiatric textbooks (e.g., Nemiah, 1985), there are virtually no systematic studies of normal developmental rituals, of childhood superstitions, nor of the early developmental history of OCD patients. Addressing this question of developmental continuity is of both theoretical and practical importance, as the identification of a group of risk for OCD would facilitate treatment and research.

In the past decade there has been an explosion of information regarding childhood Obsessive Compulsive Disorder (Rapoport, 1986, 1989; Swedo et al., 1989). Nearly onethird of adult obsessional patients reported the onset of their symptoms before the age of 15 years (Black, 1978), and cases as young as age 3 with presentations virtually identical to those seen in adults have been reported (Judd, 1965; Adams, 1973). Childhood OCD is now recognized as a relatively common disorder with intriguing biological links (Rapoport, 1989a,b). Because the disorder is more widely recognized, large numbers of patients of all ages have become available for study, and the question of whether there is a continuum between developmental rituals, superstitions, and $O C D$ can be systematically addressed.

Data from the National Institute of Mental Health (NIMH)

Accepted June 27, 1989.

From the Child Psychiatry Branch, National Institute of Mental Health, Building 10, Room 6N-240, Bethesda, Maryland 20892.

The authors thank Carolyn Zahn-Wechsler, Ph.D., and Kathleen Free, Ph.D, for their helpful comments and Mitsuko Perry Shannon for her assistance in data collection.

Reprints requests to Dr. Leonard, Child Psychiatry Branch, National Institute of Health, Bldg. 10, Room 6N240, Bethesda, MD 20892.

$0890-8567 / 90 / 2901-0017 \$ 2.00 / 0 \bigodot 1990$ by the American Academy of Child and Adolescent Psychiatry. series of over 70 children and adolescents with severe primary OCD permitted us to identify major patterns of symptoms in a large population (Swedo et al., 1989). The OCD symptom pattern does not appear to be artifact of referral bias, as it was also representative of that seen in a community sample (Flament et al., 1988). The initial clinical impression of these study populations suggested that they did not differ from normal peers with respect to number or intensity of rituals or of superstitions. For this reason, a systematic study was undertaken to compare developmental rituals and superstitions in OCD patients and normal controls.

In the present report, the literature on childhood rituals and superstitions is reviewed, their appropriateness as models for OCD is discussed, and developmental data from a subgroup of obsessive compulsive children and controls is presented.

\section{Normal Developmental Rituals}

Anna Freud (1965) emphasized the normality of childhood repetitive behaviors but did not attempt to quantify them. At $2 \frac{1}{2}$ years of age, some ritualistic behavior becomes evident in most children, but the exact frequency is not known. Gesell et al. (1974) noted that at about this age, previously malleable toddlers will begin to expect routines and to require things to be done "just so." Transitions are difficult and the familiar way is preferred, particularly at mealtimes, bathing, and bedtimes. Gesell referred these as the "ritualisms of the ritualist." Anxiety about separation, as well as developmental issues of mastery and cognitive control, are assumed to play important roles (Gesell et al., 1974).

Generally, by age 3 or 4 , children start to become less rigid about their rituals and may give up some and take less time with others. By age 4, children seem to be more comfortable dealing with changes, although significant bedtime ceremonies and ritualistic behaviors can still be seen in normal 4- to 6-year-olds (Nagera, 1980). The sleep disturbances, nightmares, and fears of the dark which lead to ritualistic requests for another story, or some other reas- 
surance are usually gone by age 8 or 9 (van Amerongen, 1980).

Early ritualized play is solitary but later develops into collective play. For example, a 3- to 5-year-old child might pretend daily to prepare a certain meal while another child might repeatedly line up trains in the same route. Between 5 and 6 years of age, children's ritualizations are characterized by group play with games like jump rope, jacks, and hopscotch, which have elaborate rules and rhymes (Rubin, 1983). Here, comparisons with obsessive compulsive (OC) behavior become more compelling. For example, the rules of those games (e.g., three skips forward, touch, turn around twice) may resemble those of an OCD ritual in which touching or moving a certain way for a number of times may occur.

From age 6 to 11 years, elaborate rules and prohibitions dominate play. Oremland (1973) described "the jinx game," a popular game of 7- to 11-year-old children. If two children happen to say the same word simultaneously, the one who says "jinx" first is in "control," and the jinxed children must remain silent until he is freed. Around age 6, boys' play expresses their belief that girls have a mysterious pernicious influence. "Cooties" is yelled out as boys avoid being touched by "contaminated" girls (Adams, 1973). A variety of tag games also manifest this theme of contamination and avoidance. Obsessions which focus on contamination could be considered to be pathological variants of these normal "contamination fears."

By age 7, children normally start collections of objects and develop hobbies. Popular collectibles such as baseball cards, miniature cars, action figures, matchbooks, or toys from the "latest" cartoon or television shows acquire great significance. Hoarding (implying the saving of worn out or useless things) is relatively common in OCD but differs from "collecting" hobbies where objects are sentimental and meaningful to their peers.

In early adolescence, an "obsession" with an activity or a rock idol or moviestar is common. Teenagers may spend days playing "Dungeons and Dragons," the computer game "Nintendo," or acting out characters from "Star Wars." They often dress like their favorite rock star and play the same song repeatedly. The analogy with $O C D$ fails because focused preoccupations on fads or popular interests are not typical of obsessive-compulsive symptomatology.

Indeed, this distinction between normal developmental "focused interests" and pathological obsessive "circumscribed interests" and "impulsions" was made over 40 years ago. Bender and Schilder's (1940) case descriptions of children with "impulsions" sound similar to those of OCD patients, but no follow-up data are given. Robinson and Vitale (1954) describe three boys with "near obsessive circumscribed interest" in transportation system, maps, trolley routes, astronomy, electricity, and railways. Interestingly, one of these children barked and cleared his throat suggesting that he may have had Tourette's syndrome, thought to be related genetically to some types of OCD (Pauls et al., 1986).

The few systematic studies of rituals are not particularly illuminating. A study of 12 white upper-middle-class chil- dren from 3 to 8 years of age concluded that many rituals, such as requests for glasses of water, reflect a social need for delaying bedtime (Albert et al., 1979). Simonds and Parraga (1984) compared bedtime behaviors and sleep disturbances in 150 children and adolescents in a psychiatric clinic with 309 nonclinic subjects in the only study to assess the frequency of sleep-related behaviors for clinical and nonclinical groups of children. (It should be noted that the clinic group had more males and a younger mean age than the nonclinic group, and 15 of the 150 psychiatric clinic sample had no psychiatric diagnosis.) The psychiatric patients exhibited more sleep problems, with $26 \%$ of the psychiatric clinic patient and $8 \%$ of nonclinic subjects exhibiting reluctance to go to sleep.

Luskin (1981) studied the rituals of greeting and leavetaking in young children through naturalistic observation and a structured "pretend" telephone conversation. Not surprisingly, greeting and leave-taking rituals were found to be related to situation and to age and are presumed to be involved in acquiring social behavior.

In summary, ritualized behavior begins early in childhood and continues throughout development. At a young age it is most characterized by bedtime rituals and the requirement that things be "just so." Later formalized games, collecting, and focused interest predominate. The similarities between normal developmental and OCD rituals include needing things to be "just so," counting and having lucky numbers, and having bedtime as a frequent time for the rituals. In contrast, OCD rituals have a later mean age of onset than developmental rituals, are distressing if not performed, are ego-dystonic, interfere in one's life, and have the hallmark features of washing, checking, and repeating (Swedo et al., 1989). Normal developmental rituals have a presumed role in mastering anxiety and enhancing one's socialization, whereas OCD rituals are emotionally distressing, isolating, and incapacitating. No continuum between the rituals of normal development and of OCD has as yet been documented.

\section{Childhood Superstitions}

Webster's Dictionary defines superstition as "a belief, conception, act or practice resulting from ignorance, unreasoning fear of the unknown or mysterious conception of causation." Marmor adds that they are "beliefs or practices without foundation in themselves and inconsistent with the degree of enlightenment reached by the community in which they exist" (Jahoda, 1974, p. IX). Superstitions, unlike rituals, are based on some magical or supernatural idea thought to bring good luck or ward off bad fortune.

The number of superstitious beliefs and practices in this country is conservatively estimated at 80,000 (Marmor, 1956). The most common superstitions in the United States are thought to bring good luck (finding four-leaf clover, keeping found pennies or rabbit's foot, or wishing on a falling star) or to avoid bad luck (not crossing black cat's path or walking under a ladder, never breaking a mirror, and avoiding the number 13). Noticably missing are washing and grooming superstitions.

A variety of conceptual models for superstitions have 
been proposed. Psychoanalytic theory speculated about their role in anxiety reduction and their similarity with society's taboos (Freud, 1950), their role as manifestations of the collective unconscious (Jung, 1956), their role in symbolizing sexual unconscious conflicts (Fliess, 1944), or their role in dealing with the fear of retaliation for boasts of good fortune (Marmor, 1956). On the other hand, social psychologists have viewed superstitions as a shift to an external "locus of control." A high superstitious belief score was positively correlated with "externality" for an experimental group of student teachers (Peterson, 1978).

A learning model was first suggested by Skinner (1953) who thought that superstitions result from a single powerful stimulus and a learned response, e.g., a child having had a bad experience with a dog may fear all dogs. Other researchers have attempted experimental human studies of such an operant learning paradigm, including laboratory teaching of superstitions to children and adolescents (Zeiler, 1972; Feingold, 1978; Wagner, 1983; Higgins, 1984), with modest success. Observing models simulating superstitions behavior is influential in increasing the behavior (Pole et al., 1974; Hamm, 1974; Dashefsky, 1979).

Plug's (1976) review of the literature on superstitions found that the majority of the studies were poorly done, out-dated, and conflicted one another. The early literature and the more recent reports of the relationship between age (Wagner, 1928; Thouless and Brown, 1964), sex, (Blum and Blum, 1974), intelligence (Killen et al., 1974), education (Pasachoff et al., 1970), and environment (Blum, 1976) and superstitious beliefs are conflicting and inconsistent.

Opie and Opie (1959) have compiled the largest sample of childhood superstitious beliefs surveying 5,000 school children throughout the United Kingdom. There are no similar survey's of children's superstitions in the United States, although superstitious beliefs are certainly common. Most superstitions deal with good or bad luck objects, the reluctance to anticipate fortunate events, and safeguards from harm. Wishing is also common as evidenced by wishes made at wells, on rainbows, on falling stars, and when blowing out birthday candles. "Step on a crack, break your mother's back" is a well known rhyme to both rural and city children who superstitiously avoid the cracks in the pavement or between stones. This theme has been stylized and incorporated in many games such as hopscotch, where all the lines are avoided. The Opies found that stressful times frequently elicit superstitious behaviors. Students may bring a mascot, a good luck charm, or lucky object to tests, and have faith in new pencils which "have never written a mistake." They might also cross their fingers or touch wood to ensure that an answer is correct.

Developmentally, superstitions seem particularly understandable in young children between the ages of 2 and 6 , as the child's cognition is typified by magical thinking with no concept of probabilities (Piaget, 1969). There is "magic power" in thoughts, words, and deeds (Wilder, 1975) and the child believes in make-believe and magic. "Undoing," an act to prevent the consequences of a frightening thought, can be normal in 6- to 8-year-olds. Common examples of magical undoing are crossing one's fingers to negate a thought or to protect oneself while telling a lie (Berman, 1979).

The most elaborate, prevalent, and strongly ingrained superstitious beliefs and sayings are found in older children, adolescents, and adults participating in competitive sports (Becker, 1975). Indeed, the best descriptive studies of superstition and rituals have been those examining sport superstitions (Becker 1975; Buhrman et al., 1982; Buhrman and Zaugg, 1983). Magical/superstitious/religious practices, ranging from a team praying together before a game to elaborate private ritualized behaviors are extremely common among athletes. A player believing that his ability is constant might attribute inconsistencies in his performance to some unrelated article or behavior such as a charm, a piece of clothing, or what one had said or touched prior to the game (Neil, 1982). Stress and performance anxiety clearly produce superstitious behavior in otherwise rational individuals. All agree that a coach would be foolish to discourage such reassuring habits as wearing "lucky" socks or repeating ritual phrases (Becker, 1975). These sport behaviors are particularly similar to some of the more "magical" OC rituals to ward off bad things from happening.

In summary, although rituals and superstitions in normal development are not well studied in this country, most differ in content from the common symptoms of childhood obsessive compulsive disorder (contamination fears, grooming, and checking). Superstitions appear to be a natural outcome of involvement in activities of an unpredictable and often dangerous nature, with benefits such as helping athletes maintain emotional balance under pressure and contributing to team morale. In contrast, OC rituals are frequently emotionally exhausting, waste a lot of time, and are without discernible benefit.

\section{Rituals and Superstitions in Childhood OCD: A Pilot Study}

\section{Method}

Since 1976, over 100 children and adolescents with severe primary OCD have been evaluated at the NIMH (Flament et al., 1985, Swedo et al., 1989). This large prospective study of childhood onset OCD enabled a pilot study of the patient's superstitions and development rituals to be conducted. The initial clinical impression was that these patients were not particularly superstitious, nor was there a pattern of quantitatively or qualitatively unusual early developmental rituals. This hypothesis was examined in a systematic fashion by administering a semistructured interview about superstitions to a group of OCD patients, a normal control group, and one of the parents from both groups. In addition, the parents completed a semistructured interview about their child's developmental rituals. The OCD group consisted of 38 consecutive cases ( 24 boys and 14 girls) with pure primary OCD (mean age: $13.6 \pm 2.9$; range: 7 to 18 ). Normal controls (13 boys and 9 girls, mean age: $13.8 \pm 3.0$; range 9 to 18) were obtained from newspaper advertisements and screened for psychopathology with a clinical interview and with the Diagnostic Interview for Children and Adolescents (Herjanic and Campbell, 1977). 
Subjects and their parents were asked about the degree of the child's belief in common superstitions, and for the OCD patients, their timing in relationship to the onset of the child's OCD. Superstitions were rated on a 3-point scale from " 0 " (absent) to " 2 " (clear belief). Developmental rituals were assessed during two time periods, preschool (3 to 5) years and grade school (6 to 13). Rituals were scored on a 6-point scale from " 0 " (absent) to " 5 " (marked) (shown in Appendix 1).

The reliability was very high for both interviews (the intraclass correlation for two joint raters of nine ritual interviews was 1.0 , and for two raters of eight superstition interviews 0.94). The interviews were scored two ways: first, without consideration whether the superstitions or ritual resembled the child's OCD symptoms and, second, scored excluding the rituals that resembled the child's OC symptoms.

\section{Results}

Superstitions. All of the OCD children understood what was meant by superstition and almost all volunteered that these were "what everyone did" and "different from OCD." Both groups reported few current superstitions either by the children themselves, (mean superstition score [ \pm SD] for OC patients $=2.1 \pm 3.1$, [range 0 to 13 ], and for controls $=2.1 \pm 2.4$, [range 0 to 7$] ;[t=0.55$, df 1,$57 ; p=$ $0.59]$ ) or by the parents for their children (mean [ \pm SD] for OC subjects' parents $=2.1 \pm 2.2$ [range 0 to 8 ], and for parents of controls $=2.2 \pm 2.4$, [range 0 to 9]; $[t=$ $0.04, p=0.50]$ ). Although the average number of superstitions reported by the parents and children were similar, the particular superstitions reported by the child usually differed from that which their parent listed (both within the patient and the control groups). Thus, the validity of these observations is uncertain, possibly because superstitions held by children are not shared with their parents.

\section{Developmental Rituals}

Developmental rituals were first compared for the two groups without respect to current OCD symptomatology. Only 6 of $22(27 \%)$ control children were rated as having had at least one marked (score $\geq 4$ ) ritualized behavior. This list included the need to have a particular blanket for sleeping, the need for stuffed animals at night to be arranged in a particular way, and the precise arranging of a stamp collection. In contrast, 24 (70\%) of the OC patient's parents rated at least one, and usually two or three ritual behaviors as having been marked. Thus, on this analysis the total score for OC patients was higher (mean $\pm S D=19.3 \pm 9.4$, range 2 to 42 ) than that of controls (mean $\pm \mathrm{SD}=12.9$ \pm 5.31 , range 4 to $20 t=6.46 p=0.001$ ). When rituals resembling obsessive symptoms were excluded, the overall mean $( \pm$ SD) for the patients $(12.7 \pm 5.8)$ did not differ from that of controls $(t=0.30 p=\mathrm{NS})$. Developmental scores were also calculated for preschool (age 2 to 5) and grade school (age 6 to 12) periods for the controls and for the patient group. Scores were obtained with and without rituals related to the patients particular obsessive compulsive symptoms.
When all rituals are included, patients differed significantly from controls both during preschool (mean score for patients, $13.3 \pm 7.9$ vs. $9.3 \pm 4.2$ for controls, $t=2.16$, $\mathrm{p}=0.3$ ) and grade schools periods (patients $6.1 \pm 3.0$ vs. $3.5 \pm 2.3 t=3.3 p=0.001$ ). However, when rituals resembling obsessive compulsive symptoms were excluded, the scores for patients were, as above, virtually identical to those for controls for both age periods (Mean 9.2 \pm 4.9 and $3.4 \pm 2.7$ for preschool and grade school respectively; $p=\mathrm{NS})$.

Table 1 shows the sex, index age, age of onset of OCD, and major OCD symptom for the 24 OCD patients with pronounced early ritualistic behaviors. Comparable data are also given for controls for whom marked rituals were recollected by their parent.

As seen in Table 1, there is a considerably longer list of pronounced rituals recalled for patients than for controls, and many of these recollected early rituals resembled the patients' primary OC symptoms.

\section{Discussion}

Although no differences between the OCD and normal control groups were found in the frequency of childhood superstitions, the OC patients were identified by their parents as having significantly more ritualized behaviors in childhood.

There are several possible interpretations of these results. First, it is well established that parents differentially recall past behaviors of their children in a fashion biased toward that of the child's current state (Yarrow, et al., 1970). The parents of OCD children, particularly those whose child had been in psychological treatment, might well recall such ritualistic behaviors more completely than parents of controls. Second, OCD itself may begin as minor, short-lived episodes of repetitive behaviors. These behaviors, retrospectively labeled as rituals, may actually have been early subclinical bouts of the disorder. Third, these exaggerated rituals might represent true behavioral "markers" of subjects at risk for the disorder and indicate a continuity between childhood onset OCD and normal developmental ritualistic behaviors.

The present data do not allow for distinguishing among these possibilities. Whether the increased childhood rituals are markers for children at risk, early subclinical microepisodes of the disorder, or an artifact of biased parental recall, can only be determined by prospective longitudinal studies with large community-based populations. These preliminary results suggest that such studies might be in order.

From both the literature review and the patient interviews, it appears that OCD is not on a continuum with superstitions. Although anxiety intensifies both OCD symptoms and superstitious behavior (as with sports rituals), this appears to be the only similarity. In contrast, the differences between OCD and superstitions in respect to intensity, role, and context are striking. The relationship between the rituals of OCD and those of normal development is more complex. Both occur most often at bedtime, leave-taking, and in stressful situations. In addition, they often share a theme of mastery, control, and maintaining order. However, differ- 
TABLE 1. Patient OCD Symptom and Development Rituals Reported as "Marked" (score $\geq 4$ ) for Childhood Onset Obsessive Compulsives $(N=24)$ and Normal Controls $(N=6)$

\begin{tabular}{|c|c|c|c|c|c|}
\hline $\begin{array}{l}\text { Patient/ } \\
\text { Control }\end{array}$ & Sex & $\begin{array}{c}\text { Index } \\
\text { Age }\end{array}$ & $\begin{array}{l}\text { Age Onset } \\
\text { of OCD }\end{array}$ & Major OCD Symptoms & $\begin{array}{l}\text { Ritual(s) Considered Pronounced } \\
\text { (Parent's Retrospective Rating) }\end{array}$ \\
\hline \multicolumn{6}{|c|}{ Parental recall for OC patients } \\
\hline $1^{a}$ & $\mathbf{M}$ & 15 & 10 & $\begin{array}{l}\text { Thoughts; worry about germs; religious; need for } \\
\text { reassurance }\end{array}$ & $\begin{array}{l}\text { Hoarding; everyday with brother, took toys out of bin, } \\
\text { one got in and other sat on top }\end{array}$ \\
\hline $2^{a}$ & M & 15 & 10 & $\begin{array}{l}\text { Hoarding; everything in right place; worries about } \\
\text { germs; religious; perfection }\end{array}$ & Hoarding; same ritual as above \\
\hline 3 & $\mathrm{~F}$ & 16 & 10 & Washing; arranging objects; some checking & Same book read every night \\
\hline 4 & $\mathbf{M}$ & 7 & 3.5 & Hoarding; touching rituals, repeating & Hoarding-Collected junk out of magazines \\
\hline 5 & $\mathbf{M}$ & 8 & 6 & Washing & $\begin{array}{l}\text { Vegetarian; said good night in certain way; hoarder (if } \\
\text { mom did not throw away, he would be "buried"'); col- } \\
\text { lecting }\end{array}$ \\
\hline 6 & F & 15 & 7 & Check; wash; things in right place; religious fears & $\begin{array}{l}\text { Ate in special order, only special foods and would not } \\
\text { eat them if they touched; adamant about how she'd wash } \\
\text { and bathe; time arranging room-hoarder }\end{array}$ \\
\hline 7 & M & 11 & 10 & Repeat; wash; Checking; arrange; ritualized walking & $\begin{array}{l}\text { Arranging every-night blanket certain way, animals cer- } \\
\text { tain way; light on }\end{array}$ \\
\hline 8 & F & 11 & 8 & Checking; arranging; straightening & $\begin{array}{l}\text { Toys certain way (did not want to play-it would mess } \\
\text { mess them up) }\end{array}$ \\
\hline 9 & $\mathbf{F}$ & 12 & 12 & Thoughts; fear of hurting self & Hoarder \\
\hline 10 & $\mathbf{M}$ & 16 & 11 & Check; wash; rinse \& check in numbers & $\begin{array}{l}\text { Hours spent on intricate Lego play; hoarder-kept every- } \\
\text { thing, but neatly }\end{array}$ \\
\hline 11 & M & 11 & 11 & $\begin{array}{l}\text { Washing; fear of stealing or going to hell; need for } \\
\text { symmetry }\end{array}$ & Hours spent on intricate Lego play; hoarder \\
\hline 12 & F & 16 & 7 & Check; wash & Hoarder \\
\hline 13 & $\mathrm{M}$ & 15 & 10 & Wash; worry about harm to self or family & $\begin{array}{l}\text { Had to sleep with certain blanket; hours spent rolling } \\
\text { toy back and forth; hoarder }\end{array}$ \\
\hline 14 & $\mathbf{M}$ & 15 & 9 & $\begin{array}{l}\text { Wash; order possessions; check; tune; avoids dirty } \\
\text { things }\end{array}$ & $\begin{array}{l}\text { Hours spent lining up matchbox cars; very concerned } \\
\text { with rules }\end{array}$ \\
\hline 15 & $\mathbf{M}$ & 17 & 8 & $\begin{array}{l}\text { Touch; repeat; numbers everything; done certain way; } \\
\text { order }\end{array}$ & $\begin{array}{l}\text { Ate in certain order; spent hours lining up matchbox cars } \\
\text { and trucks perfectly }\end{array}$ \\
\hline 16 & $\mathrm{M}$ & 17 & 16 & Wash; avoids contaminated things & $\begin{array}{l}\text { Hoarder; never threw anything away, kept old shoes that } \\
\text { no longer fit }\end{array}$ \\
\hline 17 & $\mathbf{M}$ & 8 & 7 & Wash; bathroom; checking; things in right place & $\begin{array}{l}\text { Hours spent on completing Lego play structures; game } \\
\text { with wheels in grocery store with very particular rules }\end{array}$ \\
\hline 18 & $\mathbf{M}$ & 13 & 7 & Wash; avoids contaminated things & $\begin{array}{l}\text { Elaborate games; no one could touch his toys; careful } \\
\text { about arranging collections }\end{array}$ \\
\hline 19 & $\mathrm{~F}$ & 10 & 7 & Check; wash clothes; shoes have to be perfect & Had to get in and out of bed on certain side \\
\hline 20 & $\mathbf{M}$ & 10 & 10 & Check; wash; repetitive thought patterns; fear of dying & $\begin{array}{l}\text { Never could stand dirt on hands; liked to bathe; very } \\
\text { concerned with rules (so much others did not want to } \\
\text { play with him); particularly neat with collection }\end{array}$ \\
\hline 21 & M & 18 & 14 & $\begin{array}{l}\text { Thoughts; check; wash; does things even number of } \\
\text { times }\end{array}$ & $\begin{array}{l}\text { Constant smashing dolls together; hours spent playing } \\
\text { Atari in ritualistic fashion }\end{array}$ \\
\hline 22 & F & 16 & 11 & $\begin{array}{l}\text { Wash; repeating; fear of being possessed, of rabies, } \\
\text { \& AIDS }\end{array}$ & $\begin{array}{l}\text { Rocked in crib for hours; routine; hours (all day) playing } \\
\text { "Blessed Mother" game }\end{array}$ \\
\hline 23 & M & 14 & 10 & $\begin{array}{l}\text { Check; wash; repeat; touch; bathroom rituals; some } \\
\text { hoarding }\end{array}$ & $\begin{array}{l}\text { Made elaborate drawings; elaborate Lincoln Log build- } \\
\text { ings; time spent collecting }\end{array}$ \\
\hline 24 & $\mathbf{M}$ & 7 & 6 & $\begin{array}{l}\text { Contamination; handwashing; bedtime rituals re: } \\
\text { counting }\end{array}$ & $\begin{array}{l}\text { Hours spent on elaborate Lego play; symmetrical and } \\
\text { very particular }\end{array}$ \\
\hline \multicolumn{6}{|c|}{ Parental recall for normal controls } \\
\hline $1 \mathrm{~PB}$ & $\mathrm{~F}$ & 16 & & & Stamp collection, time spent arranging it "just so" \\
\hline $2 \mathrm{DH}$ & $\mathbf{F}$ & 17 & & & ald not sleep without \\
\hline $3 \mathrm{KS}$ & $\mathrm{F}$ & 15 & & & Bell collection, very particular, must be "just so" \\
\hline $4 \mathrm{DL}$ & $\mathrm{F}$ & 18 & & & $\begin{array}{l}\text { Arranged stuffed animals around her always the same } \\
\text { way }\end{array}$ \\
\hline $5 \mathrm{MB}$ & F & 11 & & & Time spend before bed arranging room and stuff animals \\
\hline $6 \mathrm{TH}$ & M & 16 & & . & Played Lego-building and taking apart and rebuilding \\
\hline
\end{tabular}

a Note: Patients 1 and 2 are monozygotic twins. 
ences in timing (rituals fade by age 8 , whereas childhood OCD usually presents after age 7) and developmental role (normal rituals enhance socialization, help master anxiety, and generally further development, while those of OCD do not) seem to separate normal developmental rituals from those of OCD.

Finally, the pilot data and literature review presented here do not fully answer the question of developmental continuity and dimensionality of obsessive-compulsive symptoms. Other psychological dimensions not subsumed under superstitions or rituals, may show continuity with OCD. For example, Rozin and coworkers $(1984,1986,1987)$ showed that laws of sympathetic magic, thought to apply primarily to individuals in traditional cultures, apply as well to normal American college students participating in studies of disgust and contamination. Rozin's measures could well represent a dimension that could be manipulated in pharmacological research or serve as a psychological marker for OCD.

\section{Appendix}

\section{A. Superstition Questionnaire}

Children and their parents were asked about age period and degree of belief (rated on a three-point scale) for the following questions:

1. Do you (does your child) have a lucky number?

2. Do you believe that seeing a black cat brings bad luck?

3. Do you believe that walking under ladders is bad luck? Would you avoid it?

4. Do you believe that the number 13 is unlucky?

5. Do you believe that opening an umbrella inside is bad luck? Would you avoid it?

6. Do you avoid stepping on the cracks in the sidewalk for fear of bringing bad luck.

7. Do you believe that finding a four leaf clover brings good luck?

8. Do you believe that picking up a penny brings good luck?

9. Do you believe that rabbit feet are lucky?

10. Do you have a lucky object? What is it?

11. Do you believe that wishes made in a well or while tossing coins in a fountain will come true?

12. Do you believe that knocking on wood will prevent the undoing of something good you have just said? Do you knock on wood?

13. Do you believe in haunted houses or ghosts?

14. Do you believe that fortune tellers can predict the future?

15. If you went to a fortune teller and she predicted something, would it come true for you?

16. Do you do something special to bring good luck? What is that?

17. Do you do something special to prevent bad luck? What is that?
18. Do you have a lucky saying? What is that?

19. Do you have a superstition that I haven't asked about? What is that?

20. When playing sports, are there certain things you do (dress in a certain way, eat certain things, do things in an order, rituals, tapping, repeating words) that help your game? What is that?

\section{B. Developmental Rituals}

Parents were asked to rate patterns that were predictable, comfortable, and safe for the children when they were young. These were rated on a 6-point scale from 0 (none) to 6 (behaviors pronounced). The following questions addressed ages 2 to 5 :

1. Liked to do things exactly the same way
A. Eating (order, choice, foods can't touch)
B. Bathing (order, certain toys, excessive wash)
C. Bedtime rituals:
bathroom
arranging room/animals
getting into bed
being kissed a special way
saying good night a certain way

2. Did you child have a lot of trouble going to bed?

Sleep disturbance

Nightmares

Fear of dark, ghosts, monsters

3. Do you recall games with specific or elaborate rules?

A. Alone (examples please)

dolls, toys

playing a certain game over and over

B. And when older, games in groups (examples?) jump rope, jacks, hopscotch

4. Do you recall your child being preoccupied with having cooties?

The following questions are concerned with when your child wás aged 6 to 12:

5. Do you recall your child having time-consuming hobbies such as working on baseball cards, stamp collection, matchbook collections?

Did everything have to be arranged "just so"?

Do you recall your child having hoarding behaviors?

\section{References}

Adams, P. (1973), Obsessive Children. New York: Penguin Books.

Albert, S., Amgott, T. \& Krakow, M. et al. (1979), Children's bedtime rituals as a prototype rite of safe passage. J. Psychol. Anthol. 2:85105.

Becker, J. (1975), Superstition in sport. Int. J. Sport Psychology, 6:148-152.

Bender, L. \& Schilder, P. (1940), Impulsions: A specific disorder of the behavior of children. Arch. Neurol. Psychiatry, 44:990-1008.

Berman, S. (1979), The psychodynamic aspects of behavior. In: Basic Handbook of Child Psychiatry, Vol. II, ed. J. Noshpitz. New York: Basic Books.

Black, A. (1978), The natural history of obsessional neurosis. In: Obsessional States, ed. H. R. Beech. London: Methuen. 
Blum, S. H. (1976), Some aspects of belief in prevailing superstitions. Psychol. Reports, 38:579-582.

- Blum, L. H. (1974), Dos and don'ts: an informal study of some prevailing superstitions. Psychol. Reports, 35:567-571.

Buhrmann, H.G. \& Zaugg, M. K. (1983), Religion and superstition in the sport of basketball. J. Sport Behav. 6:146-157.

- Brown, B. \& Zaugg, M. K. (1982), Superstitious beliefs and behavior: A comparison of male and female basketball players. $J$. Sport Behav., 5:175-185.

Dashefsky, P. R. (1979), An operant investigation of the development of human superstitious behavior. Diss. Abstracts, 40:2358-B.

Feingold, B. D. (1978), Superstition as a strategic research site for the investigation of belief. Diss. Abstracts, 38:5059-5060.

Flament, M., Rapoport, M., Berg, C. et al. (1985), Clomipramine treatment of obsessive compulsive disorder: a double blind controlled study. Arch. Gen. Psychiatry, 42:977-983.

Whitaker, A., Rapoport, J. L. et al. (1988), Obsessive compulsive disorder in adolescence: an epidemiological study. J. Am. Acad. Child Adolesc. Psychiatry, 27:764-771.

Fliess, W. (1944), Knocking on wood. A note on the preoedipal nature of the magic effect. Psychoanalytic Quarterly, 13:327-340.

Freud, A. (1965), Normality and Pathology in Childhood. New York: International Universities Press.

Freud, S. (1950), Totem and Taboo. London: Routledge \& Kegan Paul, Ltd.

Gesell, A., Ames, L. B. \& Ilg, F. L. (1974), Infant and Child in the Culture Today. New York: Harper and Row.

Hamm, P. (1974), An experimental investigation of socially mediated acquisition of superstitious behavior in children. Diss. Abstracts, 34:3532-B

Herjanic, B. E. \& Campbell, J. W. (1977), Differentiating psychiatrically disturbed children on the basis of a structured interview. $J$. Abnorm. Child Psychol, 5:127-135.

Higgins, S. T. (1984), The social transmission of superstitions: Operant behavior. Diss. Abstracts, 44:3561-B.

Jahoda, G. (1984), The Psychology of Superstition. New York: Jason Aronsen Company.

Judd, L. L. (1965), Obsessive compulsive neurosis in children. Arch. Gen. Psychiatry, 12:136-143.

Jung, C. G. (1956), Collected Works, Vol. 5. London: Kegan Paul.

Killen, P., Wildman, R. \& Wildman, R. (1974), Superstitiousness and intelligence. Psychol. Report, 34:1158.

Leonard, H., Swedo, S., Rapoport, J., Lenane, M. \& Cheslow, D. (1988), Treatment of childhood obsessive compulsive disorder with clomipramine and desmethylimipramine: A double-blind crossover comparison. Psychopharmacol. Bull 24:93-95.

Luskin, B. R. (1981), The development of ritual greetings and leave takings in young children. Diss. Abstracts, 41:2827-B.

Marmor, J. (1956), Some observations on superstition in contemporary life. Amer. J. Orthopsychiatry, 13:119-130.

Nagera, H. (1980), The four-six year stage. In: The Course of Life, Vol. I, Infancy and Early Childhood, ed. S. Greenspan and G. Pollock. Washington, DC: DHHS Publication.

Neil, G. I. (1982), Demystifying sport superstition. Int. Rev. Sport Sociology, 17:99-124.

Nemiah, J. (1985), Obsessive compulsive disorder. In: Comprehensive Textbook of Psychiatry, ed. H. Kaplan \& B. Sadock. Baltimore: Williams and Wilkins.

Opie, P. \& Opie, I. (1959), The Lore and Language of school children. London: Oxford University Press.

Oremland, J. D. (1973), The jinx game. Psychoanalytic Study of the Child, 28:419-431.
Pasachoff, J. M., Cohen, R. J. \& Pasachoff, N. W. (1970), Belief in the supernatural among Harvard and West African University students. Nature, 227:971-972.

Pauls, D. L., Towbin, K., Leckman, J. F. et al. (1986), Gilles de la Tourette's Syndrome and obsessive compulsive disorder. Arch. Gen. Psychiatry, 43:1180-1182.

Peller, L. (1954), Libidinal phases, ego development and play. Psychoanalytic Study of the Child, 10:178-199.

Peterson, C. (1978), Locus of control and belief in self-oriented superstitions. J. Soc. Psychol. 105:305-306.

Piaget, J. (1969), The Child's Conception of the World. Paterson, NJ: Littlefield, Adams \& Co.

Plug, C. (1976), The psychology of superstition: Psychologia Africana, 16:93-115.

Pole, J., Berenson, N. \& Sass, D. (1974), Walking under a ladder, a field experiment on superstitious behavior. Perspective of Social Psychol. Bull., 1:10-12.

Rapoport, J. L. (1986), Annotation: Childhood obsessive compulsive disorder. J. Child Psychol. Psychiatry, 27:289-295.

- (ed.) (1989a), Obsessive Compulsive Disorder in Children and Adolescents. Washington, DC: American Psychiatric Press.

- (1989b), Neurobiology of obsessive compulsive disorder. JAMA, 260:2888-2890.

Robinson, J. F. \& Vitale, L. J. (1954), Children with circumscribed interest patterns. Amer. J. Orthopsychiatry, 24:755-766.

Rozin, P., Fallon, A. \& Mandell, R. (1984), Family resemblance in attitudes to foods. Dev. Psychol., 20:309-314.

_ Millman, L., \& Nemeroff, C. (1986), Operation of the laws sympathetic magic in disgust and other domains. J. Pers. Soc. Psychol., 50:703-712.

- Fallon, A. (1987), A perspective on disgust. Psychol. Rev. 94:23 41

Rubin, K. H., Fein, C.G. \& Vandenberg, G. (1983), Play. In: Handbook of Child Psychology, Vol. 4., ed. P. Mussen, New York: Wiley \& Son.

Simonds, J. E. \& Parraga, H. (1984), Sleep behaviors and disorders in children and adolescents evaluated at Psychiatric Clinics. J. Dev. Behav. Pediatrics, 5:6-10.

Skinner, B. F. (1953), Science and Human Behavior. New York: McMillan Co.

Swedo, S., Rapoport, J., Leonard, H. \& Lenane, M. (1989), Childhood obsessive compulsive disorder: Clinical phenomenology of 70 cases. Arch. Gen. Psychiatry, 46:335-341.

Thouless, R. H. \& Brown, L. B. (1964), Petitionary prayer-belief in its appropriations and causal efficacy among adolescent girls. In: From Religious Experience to a Religious Attitude, ed. A. Goden. Brussels: Lunnen Vitae Press.

Van Amerongen, S. T. (1980), Latency and prepubertal children. In: Basic Handbook of Child Psychiatry, Vol. III, ed., J. Noshpitz. New York: Basic Books.

Wagner, M. E. (1928), Superstitions and their social and psychological correlatives among college students. Journal of Education Society, Vol. 2, 2:26-36.

Wagner, G. A. (1983), The acquisition of superstitious behavior in children. Diss. Abstracts, 43;3762.

Wilder, J. (1975), The lure of magic thinking. Amer. J. Psychother., 29:37-55.

Yarrow, M. R., Campbell, J. D. \& Burton, R. V. (1970), Recollections of childhood: a study of retrospective method. In: Monograph of the Society of Research and Child Development, \#35.

Zeiler, M. (1972), Superstitious behavior in children: an experimental analysis. Advances in Child Development and Behavior, 7:2-29. 